baboons that I could see at the time were not unduly alarmed at my presence once they had reached the top of the cliff.

\section{Martin Pickford}

Department of Geology,

Queen Mary College,

University of London,

Mile End Road,

London E1 4NS, UK

1 Hamilton, W. J., Buskirk, R. E., and Buskirk, W. H., Nature, 256, 488 (1975).

\section{H-2 antigen restriction of viral infection}

KosZINowsKı and Ertl demonstrated ${ }^{1}$ that $\mathbf{T}$ lymphocytes immunised in vivo against virus kill virus-infected target cells only when these share $\mathbf{H}-2$ antigens with the effector cells ${ }^{2}$. The commonly expressed view ${ }^{3}$ is that the effector $\mathrm{T}$ cells recognise an antigen created by an interaction of $\mathrm{H}-2 \mathrm{~K}$ or $\mathrm{H}-2 \mathrm{D}$ antigen molecules with viral protein.

To obtain further support for this notion, Koszinowski and Ertl show convincingly that anti-H-2 serum blocks killing when it is directed against the target cells, but not when directed against the effector cells. An unfortunate nomenclature (for example, anti-H-2 $2^{\mathbf{k}}$ for $\left(\mathrm{H}-2^{\mathrm{d} / \mathrm{k}} \times \mathrm{H}-2^{\mathrm{bb}}\right)$ anti-H-2 $\left.2^{\mathrm{kk}}\right)$ gives the impression that the sera are directed against the antigens of the whole $\mathrm{H}-2$ complex, when in fact both antisera used are directed only against the $K$ end of the $H-2$ complex. Thus the $\mathrm{H}-2 \mathrm{D}$ antigens of the effector cells are still free, and one cannot rule out the alternative hypothesis ${ }^{1}$, that in order to kill, effector cells have to match up their SD antigens with those of the targets ${ }^{4}$.

On the other hand, cytotoxicity is blocked completely whenever the antiserum, be it an anti-H-2K or an antivaccinia serum, is directed against the target cells, and this is taken as evidence for an interaction product being the target. It is important to know whether a similar blocking could be caused by any antiserum directed against the target cells, or only by anti-H-2 or anti-virus serum. Two points are of particular interest in this respect. First, blocking of cytotoxicity is complete although the antisera cover only the $K$ end-if the blocking is as specific as in allograft reactions, where blocking the target antigens of only one end of $\mathrm{H}-2$ hardly affects the killing ${ }^{5}$, this would mean that vaccinia, unlike LCM and ectromelia virus $^{2}$, modifies only the $\mathrm{H}-2 \mathrm{~K}$ antigens. Second, one should note the blocking of $\mathrm{F}_{1}$ target cells. For example, $H-2^{k}$ effectors do not kill $H-2^{d}$ targets, but they will kill $(d \times k) \mathrm{F}_{1}$ as well as $H-2^{k}$ target cells. Killing of $H-2^{k}$ is blocked by anti-H-2 $\mathrm{K}^{\mathrm{k}}$, not by anti-H-2 ${ }^{\mathrm{d}}$, while killing of $F_{1}$ targets are blocked by both

\section{Matters arising}

Matters Arising is meant as a vehicle for comment and discussion about papers that appear in Nature. The originator of a Matters Arising contribution should initially send his manuscript to the author of the original paper and both parties should, wherever possible, agree on what is to be submitted. Neither contribution nor reply (if one is necessary) should be longer than 300 words and the briefest of replies, to the effect that a point is taken, should be considered.

antisera. If the $H-2^{k}$ effectors interact only with modified $\mathrm{H}-2^{k}$ antigens on the target cells, one should, again by analogy to the specificity in allograft reactions ${ }^{6}$, not have expected anti-H-2 ${ }^{\mathbf{d}}$ serum to have any effect on the killing of $F_{I}$ target cells by $H-2^{k}$ effector cells. My comments are based on the assumption that complete blocking is obtained only when all possible effector-target cell interactions are inhibited, and I have overinterpreted the data, if the relationship between percentage ${ }^{51} \mathrm{Cr}$-release and number of lytic interactions is less quantitative.

The field of T-cell mediated immunity to virus infected target cells is fruitful and holds promise of information about the evolutionary significance of histocompatibility antigens ${ }^{3}$. It is therefore important, before we make conclusions about mechanisms, to know to what extent the phenomenon is analogous to allograft immunity.

\section{KIRSTEN FisCher LindAhL}

Immunobiology Research Center,

1150 University Avenue,

Madison, Wisconsin 53706

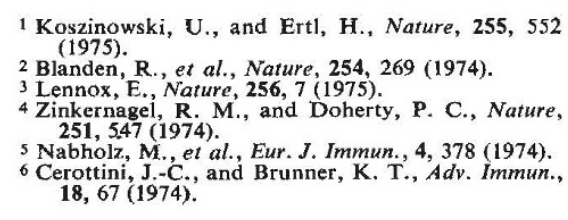

KoszinowsKi AND ERTL REPLY-We think that our data ${ }^{1}$ do not allow the interpretation that serum mediated blocking of cell-mediated cytolysis (CMC) of virus infected syngeneic cells reflects an inhibition of all possible effector-target cell interactions. We cannot express this opinion since we find inhibitory activities also with antisera directed against vaccinia virus specific surface antigens ${ }^{2}$.

The $F_{1}$ fibroblast targets were extremely sensitive for vaccinia infection which led to high spontaneous and small specific lysis. We are unsure whether the $\mathrm{H}-2^{\mathrm{d}}$ inhibition in these experiments had a significance, since unspecific blocking occurred to some extent(see Fig. 1 of ref.1). Anyway, xenogenic anti-target cell serum absorbed for $\mathrm{H}-2$ had no specific inhibitory effect.

There are indeed indications that, in the experimental conditions we used the $K$ end is the essential target. When we tested an anti-H-2 $\mathrm{D}^{\mathrm{k}}$ serum $\left(\left(\mathrm{H}-2^{\mathrm{b}} \times\right.\right.$ $\mathrm{H}-2^{\mathrm{d}}$ ) anti-K $\left.\mathrm{K}^{\mathrm{d}} \mathrm{D}^{\mathrm{k}}\right)$ we found minimal blocking activities.

These results can be explained by two possible mechanisms. Vaccinia virus alters mainly $K$-end antigens so that these modified antigens can form a target for the $T$ cell. On the other hand it is possible that $\mathrm{T}$ cells predominantly attack $K$-end alterations. Comparable results concerning different inhibitory activity on T-cell mediated killing by anti- $K$-end or $D$-end sera have recently been described in a tumour situation ${ }^{3}$.

In the ectromelia system some mouse strains (B10.A (2R), B10.A (4R)) react more strongly at the $K$ end $^{4}$. Shearer et $a l^{5,6}$ describe effector cell activity against TNP-modified cells absolutely restricted to the $K$ end in two mouse strains while other strains recognise the TNP-modified $D$ end as well. Restriction of CMC can therefore be dependent on the target cell ${ }^{5,6}$, the modifying agent and the mouse strain used, so that at present no generalised answer about $K$ - or $D$-end specificity is possible.

We think that the intimacy hypothesis? of matching unaltered self antigens is unlikely. In addition to the arguments of Zinkernagel and Doherty ${ }^{8}$ we found that the target antigen in the vaccinia infection for the CL has a close physical relationship to SD antigens ${ }^{1}$. Second, enzymatic reduction of $\mathrm{H}-2$ antigens reduces $\mathrm{CMC}$ without affecting anti-vaccinia antibody mediated cytolysis (Ertl and Koszinowski, unpublished) and third, expression of the H-2 alloantigens is altered detectably by reduced serum absorbing capacity and inhibited allogenic $\mathrm{CMC}^{9,10}$. The latter observation especially, argues against the possibility of matching normal self antigens as a prerequisite for the recognition of new antigenic determinants.

\section{Hygiene-Institut der Universität,} Kreuzbergring, West Germany

\footnotetext{
1 Koszinowski, U., and Ert1, H., Nature, 255, 552 (1975).

2 Koszinowski, U., and Thomssen, R., Eur. J. Immun., 5, 245 (1975).

${ }^{3}$ Germain, R. N., Dorf, M. E., and Benacerraf, B., J. exp. Med., 142, 1023 (1975).

(1975).

T. G and Garbarino, C. A.

J. exp. Med., 141, 1348 (1975).
Schmitt-Verhulst, A.-M., and Shearer, G. M., J. exp. Med., 142, 914 (1975)

Zinkernagel, R. M., and Doherty, P. V., Nature, 248, 701 (1974)

248, 701 (1974) M., and Doherty, P. C., Nature, 251, 547 (1974).

Gardner, I. D., Bowern, N. A., and Blanden, R. V.. Eur. J. Immun., 5, 122 (1975).

10 Koszinowski, U., and Ertl, H., Nature, 257, 596 (1975).
} 